\title{
Perdas de Rendimento de Grãos na Cultura de Arroz Irrigado em Função da População de Plantas e da Época Relativa de EMERGÊNCIA De ARROZ-VERmelho OU DE SEU Genótipo Simulador DE INFESTAÇÃO DE ARROZ-VERMELHO ${ }^{1}$
}

\author{
Grain Yield Losses in Flooded Rice Crop as a Function of Plant Population and Relative \\ Emergence Timing of Red Rice or their Genotype Simulator
}

AGOSTINETTO, D. ${ }^{2}$, FLECK, N.G. ${ }^{3}$, RIZZARDI, M.A. ${ }^{2}$ e BALBINOT JR., A.A. ${ }^{4}$

\begin{abstract}
RESUMO - O objetivo deste trabalho foi determinar a influência de populações e de épocas relativas de emergência de arroz-vermelho ou do cultivar de arroz EEA 406, cultivar considerado simulador do arroz-vermelho, no rendimento de grãos do arroz cultivado e comparar variáveis explicativas, visando identificar a que proporciona melhor ajuste dos dados ao modelo da hipérbole retangular. Para isso, foram conduzidos dois experimentos a campo na estação de crescimento 1999/00. Os tratamentos foram arranjados em esquema fatorial, sendo formados por três épocas de emergência $(-9,0$ e 8 dias em relação à emergência do cultivar IRGA 417) e por populações de arroz-vermelho (experimento 1) ou do cultivar simulador (experimento 2). O modelo de regressão não-linear da hipérbole retangular foi utilizado para descrever a relação entre perda de rendimento de grãos e variáveis explicativas. A emergência antecipada do arroz-vermelho ou do cultivar simulador, em relação à do arroz irrigado, aumentou as perdas de rendimento de grãos da cultura. $\mathrm{O}$ arroz-vermelho apresentou maior potencial de competição com a cultura de arroz, comparativamente ao cultivar simulador. População de plantas e cobertura do solo dos genótipos competidores apresentaram melhor ajuste do que massa seca como variáveis explicativas, em modelos matemáticos, para estimar perdas de rendimento de grãos em arroz irrigado.
\end{abstract}

Palavras-chave: Oryza sativa, interferência, modelos empíricos, variáveis explicativas.

\begin{abstract}
The objective of this research was to determine the influence of populations and relative emergence timings of red rice or of rice cultivar EEA 406 considered as a mimicker of red rice, on grain yield of rice crop and to compare explicative variables, to identify which one provides a better adjustment of data to the retangular hyperbolic model. Thus, two field experiments were carried out during the 1999/00 growing season. Treatments were arranged in a factorial design, consisting of three relative emergence timing $(-9,0$, and 8 days in relation to the emergence of IRGA 417 cultivar) and by plant populations of red rice (Experiment 1) or of the mimicker cultivar (Experiment 2). The non linear regression model of retangular hyperbole was tested to describe the relation between rice grain yield loss and explicative variables. Anticipation of emergence of the red rice or of its mimicker cultivar, in relation to rice emergence, increased crop grain yield loss. Red rice showed greater competition potenctial with rice than the mimicker genotype. Plant population and soil coverage by the competing genotypes presented better adjustment than dry weight as explicative variables, in the mathematical models used to estimate grain yield loss in flooded rice.
\end{abstract}

Key word: Oryza sativa, interference, empirical models, explicative variables.

Recebido para publicação em 13.10.2003 e na forma revisada em 18.6.2004.

Eng.-Agr., M.S., Aluno do Programa de Pós-Graduação em Fitotecnia da Universidade Federal do Rio Grande do Sul - UFRGS, Caixa Postal 15100, 90001-970 Porto Alegre-RS, <agostinetto@agicultura.gov.br>; ${ }^{3}$ Eng.-Agr., Ph.D., Prof. da Faculdade de Agronomia da UFRGS; ${ }^{4}$ Eng.-Agr., Aluno do Programa de Pós-Graduação em Fitotecnia da UFRGS.

Planta Daninha, Viçosa-MG, v.22, n.2, p.175-183, 2004 


\section{INTRODUÇÃO}

Dentre os fatores que afetam as relações de competição entre arroz-vermelho e arroz cultivado destacam-se as populações de plantas concorrentes e a época relativa de sua emergência. De acordo com Vandevender et al. (1997), o incremento na população de plantas daninhas aumenta as perdas de rendimento de grãos em arroz irrigado e, com freqüência, as relações entre população e rendimento não são lineares e tendem a ser funções sigmóides ou hiperbólicas. A resposta não-linear ocorre porque cada planta adicional de planta daninha em populações elevadas apresenta menor impacto relativo no rendimento da cultura do que cada planta adicional em populações relativamente baixas. Esse tipo de relacionamento entre população e rendimento da cultura provavelmente decorre da disponibilidade finita de recursos no meio (Radosevich et al., 1997).

As variações observadas nas respostas à população de plantas daninhas, entre locais e anos, geralmente associam-se às variações na época de emergência (Knezevic et al., 1997). Estudos sobre o período crítico de interferência indicam que os modelos de competição baseados na resposta do rendimento da cultura à população de plantas daninhas freqüentemente são poucos precisos, devido às variações na época de emergência e no tamanho das plantas daninhas, em relação às da cultura (Knezevic et al., 1997).

Diferenças nas épocas relativas de emergência afetam consideravelmente as habilidades competitivas das espécies envolvidas: as primeiras plântulas a emergir provavelmente apresentarão maior crescimento porque adquirem vantagem de acesso prioritário aos recursos do meio (O`Donovan et al., 1985). As plantas daninhas que emergem mais tarde do que as cultivadas em geral exercem menor impacto sobre o rendimento, pois grande parte da interferência somente ocorre após a definição dos componentes do rendimento da cultura (Vandevender et al., 1997).

A partir da constatação da importância da época relativa de emergência, foram desenvolvidos modelos matemáticos empíricos para descrever a resposta do rendimento da cultura a um ou mais fatores que caracterizem a infestação de plantas daninhas. Nesse aspecto, como resultado de uma análise de modelo, demonstrou-se que diferenças na população de plantas daninhas, entre os experimentos testados, representaram $13 \%$ da variação constatada, enquanto diferenças entre épocas de emergência da cultura e infestantes explicaram $96 \%$ da variação verificada na perda de rendimento (Kropff \& Lotz, 1992). Segundo detectaram O`Donovan et al. (1985), para cada dia que Avena fatua (aveia-silvestre) emergiu antes de cevada ou trigo, a perda de rendimento aumentou em aproximadamente 3\%. Essa perda diminuiu na mesma quantidade para cada dia que a planta daninha emergiu após a cultura. Dessa forma, ambas as variáveis, população de plantas daninhas e periodo entre a sua emergência e da cultura e a delas, costumam definir as relações de competição entre elas e, por isso, necessitam ser incorporadas em modelos matemáticos que estimem a interferência entre espécies de plantas daninhas e cultivadas.

Este trabalho foi realizado com os objetivos de avaliar a influência de populações e épocas de emergência de dois genótipos concorrentes, arroz-vermelho e cultivar de arroz EEA 406, simulador daquele, no rendimento de grãos de arroz irrigado e comparar variáveis explicativas para identificar aquela que proporciona melhor ajuste dos dados ao modelo matemático utilizado para estimar a interferência.

\section{MATERIAL E MÉTODOS}

Foram conduzidos dois experimentos a campo, na Estação Experimental do Arroz (EEA), pertencente ao Instituto Rio-Grandense do Arroz (IRGA), no município de CachoeirinhaRS, durante a estação de crescimento 1999/ 00. No primeiro experimento foi utilizado arrozvermelho como competidor do arroz; no segundo, utilizou-se como competidor o cultivar de arroz EEA 406, o qual, por apresentar características morfológicas semelhantes às do arrozvermelho, exerceu a função de simulador deste. A não-utilização do próprio arrozvermelho como infestante natural no segundo experimento deve-se ao nivel geralmente elevado de dormência de suas sementes (Agostinetto et al., 2001), o que leva à emergência desuniforme, dificultando o estabelecimento de populações predeterminadas no tempo e no espaço. 
O delineamento experimental utilizado foi o completamente casualizado, com uma unidade experimental por combinação de fatores. Cada unidade experimental (parcela) foi composta por área de $12 \mathrm{~m}^{2}$. Os tratamentos constaram dos fatores épocas de emergência dos competidores (-9, 0 e 8 dias) e populações do arroz-vermelho (cinco niveis) (experimento 1) e do cultivar simulador (13 níveis) (experimento 2).

O cultivar de arroz utilizado foi o IRGA 417, semeado em 11/12/1999, sendo a emergência oito dias após. O preparo do solo foi realizado em sistema convencional. A adubação de base foi realizada de acordo com a análise química do solo. A adubação de cobertura foi fracionada em três épocas de aplicação, aos 16, 32 e 47 dias após a emergência (DAE) do arroz cultivado, utilizando-se $90 \mathrm{~kg}$ de $\mathrm{N} \mathrm{ha}^{-1}$ no total. As demais práticas de manejo foram aquelas recomendadas pela pesquisa (Embrapa, 1999).

As avaliações de populações dos genótipos competidores, massa seca da parte aérea e cobertura vegetal do solo foram realizadas aos 15 e 30 DAE da cultura. Para determinação da variável explicativa população de plantas, foram realizadas contagens dos individuos encontrados em duas áreas de $0,25 \mathrm{~m}^{2}$ por parcela. A massa seca da parte aérea foi quantificada pela coleta e secagem em estufa a $60{ }^{\circ} \mathrm{C}$, até peso constante, das plantas colhidas em uma área de $0,25 \mathrm{~m}^{2}$ por parcela. A cobertura do solo por plantas de arroz foi avaliada visualmente em toda a parcela, de modo individual, por três avaliadores, utilizando-se escala percentual, na qual a nota zero correspondeu à ausência de cobertura do solo e a nota 100 representou cobertura completa do solo. $\mathrm{Na}$ colheita da cultura, realizada aos 122 DAE, determinou-se o rendimento de grãos em área de $7,2 \mathrm{~m}^{2}$. Após pesagem dos grãos, foi determinada sua umidade e, posteriormente, os pesos foram uniformizados para teor de $13 \%$ de umidade.

Antecedendo a análise dos dados, os valores de massa seca $\left(\mathrm{g} \mathrm{m}^{-2}\right)$ e cobertura do solo (\%) foram multiplicados por 100 , dispensandose assim o uso do fator de correção no modelo. As relações entre perdas percentuais de rendimento do arroz cultivado, em função das variáveis população, massa seca ou cobertura do solo relativas às populações de genótipos competidores, foram calculadas separadamente para cada época de emergência, utilizandose o modelo de regressão não-linear derivada da hipérbole retangular, conforme foi proposto por Cousens em 1985 (equação 1):

$$
\operatorname{Pr}=\frac{(i * X)}{\left[1+\left(\frac{i}{a}\right) * X\right]}
$$
equação 1

em que: $\operatorname{Pr}=$ perda de rendimento (\%); $X=$ população, massa seca ou cobertura do solo, relativas aos competidores; $i=$ perda de rendimento (\%) por unidade dos genótipos competidores quando a respectiva variável se aproxima de zero; e $a=$ perda de rendimento (\%) quando a variável em questão tende ao infinito.

$\mathrm{Na}$ análise de perdas de rendimento decorrentes do efeito conjunto de populações e épocas de emergência dos competidores utilizou-se o modelo de regressão da hipérbole retangular, conforme proposto por Cousens et al. em 1987 (equação 2):

$$
\operatorname{Pr}=\frac{(i * X)}{\left[\left(\exp ^{-c T}\right)+\left(\frac{i}{a}\right) * X\right]}
$$

equação 2

sendo: $T$ = época de emergência do arroz cultivado em relação aos competidores; e $c=$ parâmetro próprio do modelo. Os demais parâmetros e variáveis referidos no modelo são aqueles já descritos na equação 1 .

Os valores da variável $\mathrm{T}$ são expressos em soma térmica e foram calculados de acordo com a equação 3 :

$$
T=\sum\left[\left(\frac{t_{\max }+t_{\min }}{2}\right)-t_{b}\right] \quad \text { equação } 3
$$

em que: $t_{\max }=$ temperatura máxima do ar, diária; $t_{\min }=$ temperatura mínima do ar, diária; e $t_{\mathrm{b}}=$ temperatura-base $\left(10^{\circ} \mathrm{C}\right)$, conforme proposto por Wiese \& Binning (1987).

Quando os genótipos competidores emergiram antes da cultura, o valor de $\mathrm{T}$ foi negativo; para emergência simultânea, o valor de $\mathrm{T}$ foi zero; e, quando a emergência da cultura antecedeu à dos competidores, o valor de $\mathrm{T}$ foi 
positivo (O`Donovan et al., 1985). Os valores de $\mathrm{T}$ foram divididos por 10, para correção na aplicação da equação 2 .

O ajuste dos dados ao modelo foi realizado pelo procedimento Proc Nlin do programa computacional SAS (SAS, 1989). Para se proceder aos cálculos, utilizou-se o método de Gauss-Newton, o qual, por sucessivas iterações, estima os valores dos parâmetros nos quais a soma dos quadrados dos desvios das observações, em relação aos valores ajustados, seja mínima (Ratkowsky, 1983). Quando os valores do parâmetro $a$ (perda máxima do rendimento de grãos) foram superestimados, a assíntota foi limitada a $100 \%$. Esse procedimento é recomendado visando evitar a obtenção de perdas de rendimento superiores a $100 \%$, as quais são biologicamente irreais (Yenish et al., 1997; Askew \& Wilcut, 2001).
O valor da estatística $F$, a $5 \%$ de probabilidade, foi utilizado como critério de ajuste dos dados ao modelo. O critério de aceitação do ajuste dos dados ao modelo baseou-se no coeficiente de determinação $\left(R^{2}\right)$ e na soma de quadrados do resíduo (SQR), de modo que maior valor do primeiro e menor valor do segundo representavam ajuste mais satisfatório.

\section{RESULTADOS E DISCUSSÃO}

O modelo da hipérbole retangular de previsão de perda do rendimento de grãos de arroz por interferência do arroz-vermelho ajustou os dados para as variáveis explicativas testadas, em ambas as épocas de avaliação (Tabela 1). Os valores da estatística $F$ foram significativos para todas as variáveis explicativas nas três épocas de emergência.

Tabela 1 - Ajustes obtidos para perda do rendimento de grãos de arroz em função de população, massa seca da parte aérea, cobertura do solo e época de emergência do arroz-vermelho. IRGA/Cachoeirinha-RS, 1999/00

\begin{tabular}{|c|c|c|c|c|c|}
\hline \multirow{2}{*}{ Variável explicativa } & \multicolumn{2}{|c|}{ Parâmetro ${ }^{\underline{1} /}$} & \multirow{2}{*}{$\begin{array}{l}\text { Coeficiente de } \\
\text { determinação } \\
\qquad\left(\mathrm{R}^{2}\right)\end{array}$} & \multirow{2}{*}{$\begin{array}{c}\text { Soma de quadrados } \\
\text { do resíduo }\end{array}$} & \multirow{2}{*}{$\begin{array}{l}\text { Estatística } \\
\qquad \mathrm{F}\end{array}$} \\
\hline & $i$ & $a$ & & & \\
\hline $\begin{array}{c}15 \mathbf{D A E}^{\mathbf{2} /} \\
\text { População de plantas } \\
-9 \mathrm{dias}^{3 /}{ }^{-1} \\
0 \mathrm{dia}^{3 /} \\
+8 \mathrm{dias}^{3 /}\end{array}$ & $\begin{array}{r}12,65 \\
4,07 \\
1,67\end{array}$ & $\begin{array}{l}100,0 \\
100,0 \\
100,0\end{array}$ & $\begin{array}{l}0,92 \\
0,65 \\
0,81\end{array}$ & $\begin{array}{r}529,0 \\
2.389,2 \\
947,2\end{array}$ & $\begin{array}{r}186,6^{*} \\
32,3^{*} \\
34,4^{*}\end{array}$ \\
\hline $\begin{array}{c}\text { Massa seca } \\
-9 \text { dias } \\
0 \text { dia } \\
+8 \text { dias }\end{array}$ & $\begin{array}{l}0,91 \\
1,32 \\
1,00\end{array}$ & $\begin{array}{l}100,0 \\
100,0 \\
100,0\end{array}$ & $\begin{array}{l}0,94 \\
0,82 \\
0,81\end{array}$ & $\begin{array}{r}439,2 \\
1.241,2 \\
962,9\end{array}$ & $\begin{array}{r}225,6^{*} \\
65,8^{*} \\
33,7^{*}\end{array}$ \\
\hline $\begin{array}{l}\text { Cobertura do solo } \\
-9 \text { dias } \\
0 \text { dia } \\
+8 \text { dias } \\
\end{array}$ & $\begin{array}{l}0,40 \\
0,63 \\
0,49 \\
\end{array}$ & $\begin{array}{l}100,0 \\
100,0 \\
100,0\end{array}$ & $\begin{array}{l}0,91 \\
0,90 \\
0,90 \\
\end{array}$ & $\begin{array}{l}599,1 \\
673,2 \\
509,8 \\
\end{array}$ & $\begin{array}{r}164,3 * \\
124,7 * \\
67,3 * \\
\end{array}$ \\
\hline $\begin{array}{c}\text { 30 DAE } \\
\text { População de plantas } \\
-9 \text { dias } \\
0 \text { dia } \\
+8 \text { dias }\end{array}$ & $\begin{array}{r}10,64 \\
8,66 \\
3,25\end{array}$ & $\begin{array}{l}100,0 \\
100,0 \\
100,0\end{array}$ & $\begin{array}{l}0,96 \\
0,88 \\
0,79\end{array}$ & $\begin{array}{r}275,6 \\
832,7 \\
1.065,0\end{array}$ & $\begin{array}{r}361,9^{*} \\
100,0^{*} \\
30,1^{*}\end{array}$ \\
\hline $\begin{array}{l}\text { Massa seca } \\
-9 \text { dias } \\
0 \text { dia } \\
+8 \text { dias }\end{array}$ & $\begin{array}{l}0,20 \\
0,09 \\
0,10\end{array}$ & $\begin{array}{r}96,3 \\
100,0 \\
100,0\end{array}$ & $\begin{array}{l}0,96 \\
0,79 \\
0,38\end{array}$ & $\begin{array}{r}262,9 \\
1.420,0 \\
3.132,3\end{array}$ & $\begin{array}{r}142,4^{*} \\
57,0^{*} \\
7,6^{*}\end{array}$ \\
\hline $\begin{array}{l}\text { Cobertura do solo } \\
-9 \text { dias } \\
0 \text { dia } \\
+8 \text { dias }\end{array}$ & $\begin{array}{l}0,19 \\
0,17 \\
0,09\end{array}$ & $\begin{array}{l}100,0 \\
100,0 \\
100,0\end{array}$ & $\begin{array}{l}0,97 \\
0,73 \\
0,87\end{array}$ & $\begin{array}{r}235,3 \\
1.832,4 \\
656,8\end{array}$ & $\begin{array}{r}424,7^{*} \\
43,3^{*} \\
51,3^{*}\end{array}$ \\
\hline
\end{tabular}

1/ $i$ e $a=$ perdas de rendimento (\%) por unidade de arroz-vermelho quando o valor da variável se aproxima de zero ou tende ao infinito, respectivamente; 리 dias após a emergência do arroz cultivado; e ㅡ épocas de emergência do arroz-vermelho em relação à do arroz cultivado. * Significativo a $5 \%$ de probabilidade. 
A redução do valor estimado para o parâmetro $i$, da primeira para a terceira época de emergência, indica decréscimo no grau de competição do arroz-vermelho em relação ao arroz cultivado (Tabela 1). A redução mais expressiva foi observada na variável população de plantas. Em trabalho conduzido por Carranza et al. (1995), constatou-se que a competição intra-específica relativa (perda de rendimento por unidade de planta daninha) diminuiu quando a população de plantas daninhas aumentou. Segundo os autores, as plantas que emergiram precocemente foram cerca de 1,5 vez mais competitivas do que aquelas que tiveram emergência tardia.

As estimativas para o parâmetro $a$ indicaram perdas de rendimento superiores a 100\% na maioria dos casos avaliados (Tabela 1). Perdas máximas de rendimento superiores a $100 \%$ são biologicamente irreais e ocorrem quando a amplitude de populações de plantas daninhas é excessivamente estreita e/ou quando os maiores valores de população não são suficientes para produzir resposta assintótica de perda de rendimento (Cousens, 1985; Yenish et al., 1997; Askew \& Wilcut, 2001). Além disso, a limitação do parâmetro $a \mathrm{em}$ $100 \%$ influencia a estimativa de outros parâmetros, podendo resultar em menor previsibilidade (Streibig et al., 1989). Contudo, outros autores também observaram superestimação da assintota do modelo (Streibig et al., 1989; Swinton et al., 1994; Askew \& Wilcut, 2002).

Em ambas as épocas de avaliação, utilizando quaisquer das variáveis explicativas, houve melhor ajuste dos dados ao modelo para a primeira época de emergência do arrozvermelho (emergência antecipada). Nas outras duas épocas de emergência, a avaliação visual da cobertura vegetal do solo pelo arroz-vermelho, em geral, mostrou o melhor ajuste dos dados ao modelo (Tabela 1).

Os resultados relativos ao cultivar simulador de arroz-vermelho (EEA 406) indicaram significância para todas as variáveis explicativas e épocas de emergência estudadas, em ambas as épocas de avaliação (Tabela 2). De modo semelhante ao que ocorreu para arrozvermelho, verificou-se redução do valor estimado para o parâmetro $i$, especialmente no caso da variável população de plantas, à medida que a emergência do cultivar concorrente atrasou em relação à do arroz cultivado. Os valores estimados para o parâmetro $a$ superaram $100 \%$ para as três variáveis explicativas quando a emergência do simulador foi anterior ou concomitante com a do arroz cultivado. Nesses casos, limitou-se o valor máximo em $100 \%$.

$\mathrm{Na}$ primeira época de emergência do simulador, em ambas as épocas de avaliação, houve melhor ajuste dos dados ao modelo na seguinte ordem de variáveis: cobertura do solo>população de plantas $>$ massa seca (Tabela 2). Na segunda época de emergência, massa seca propiciou ajuste superior na avaliação de $15 \mathrm{DAE}$, enquanto a população de plantas foi satisfatória em estimar as perdas de rendimento, em especial na avaliação realizada aos 30 DAE. Na terceira época de emergência, constatou-se baixo ajuste dos dados ao modelo, o que pode ser devido, em parte, à maior dificuldade em identificar as plantas do cultivar simulador dentro da população do arroz cultivado. Além disso, o potencial competitivo do simulador deve ter sido sensivelmente menor quando sua emergência foi tardia.

Comparando os dois genótipos (arrozvermelho e cultivar EEA 406), observa-se que a variável explicativa população de plantas foi a mais responsiva às alterações na época relativa de emergência entre os genótipos concorrentes (Tabelas 1 e 2) e que o arroz-vermelho possui maior habilidade competitiva do que o cultivar simulador em afetar o rendimento do arroz irrigado. Ao comparar os valores estimados para o parâmetro $i$, o qual pode ser usado como índice de competitividade relativa entre espécies (Swinton et al., 1994), verificase que, na média das duas avaliações, o arrozvermelho foi 150 e $230 \%$ mais competitivo do que o cultivar simulador, considerando-se a primeira e segunda épocas de emergência, respectivamente. No caso dos genótipos de arroz concorrentes cujas emergências sucederam à do arroz cultivado, houve menor diferença entre eles quanto à habilidade competitiva (i). Os valores deste parâmetro ficaram aquém dos obtidos nas duas primeiras épocas de emergência, indicando redução do potencial de competição na situação de emergência tardia das plantas concorrentes.

Em ambos os experimentos, quando os genótipos competidores emergiram mais tarde que a cultura, observou-se decréscimo 
Tabela 2 - Ajustes obtidos para perda do rendimento de grãos de arroz em função de população, massa seca da parte aérea, cobertura do solo e época de emergência do cultivar EEA 406, simulador de arroz-vermelho. IRGA/Cachoeirinha-RS, $1999 / 00$

\begin{tabular}{|c|c|c|c|c|c|}
\hline \multirow{2}{*}{ Variável explicativa } & \multicolumn{2}{|c|}{ Parâmetro $^{1 /}$} & \multirow{2}{*}{$\begin{array}{c}\text { Coeficiente de } \\
\text { determinação } \\
\left(\mathrm{R}^{2}\right)\end{array}$} & \multirow{2}{*}{$\begin{array}{c}\text { Soma de quadrados } \\
\text { do resíduo }\end{array}$} & \multirow{2}{*}{$\begin{array}{c}\text { Estatística } \\
\text { F }\end{array}$} \\
\hline & $i$ & $a$ & & & \\
\hline $\begin{array}{c}15 \mathbf{D A E}^{-\frac{2}{}} \\
\text { População de plantas } \\
-9 \mathrm{dias}^{3 /}{ }^{-/} \\
0 \mathrm{dia}^{-3 /} \\
+8 \mathrm{dias}^{\underline{3} /}\end{array}$ & $\begin{array}{l}4,81 \\
1,25 \\
1,14\end{array}$ & $\begin{array}{r}100,0 \\
100,0 \\
25,2\end{array}$ & $\begin{array}{l}0,75 \\
0,78 \\
0,47\end{array}$ & $\begin{array}{r}3452,5 \\
1345,8 \\
449,8\end{array}$ & $\begin{array}{l}92,0^{*} \\
93,8^{*} \\
22,8^{*}\end{array}$ \\
\hline $\begin{array}{l}\text { Massa seca } \\
-9 \text { dias } \\
0 \text { dia } \\
+8 \text { dias }\end{array}$ & $\begin{array}{l}0,32 \\
0,31 \\
1,27\end{array}$ & $\begin{array}{r}100,0 \\
100,0 \\
19,3\end{array}$ & $\begin{array}{l}0,64 \\
0,81 \\
0,23\end{array}$ & $\begin{array}{r}4999,6 \\
1144,5 \\
654,7\end{array}$ & $\begin{array}{r}59,8 * \\
112,3 * \\
13,9 *\end{array}$ \\
\hline $\begin{array}{l}\text { Cobertura do solo } \\
-9 \text { dias } \\
0 \text { dia } \\
+8 \text { dias } \\
\end{array}$ & $\begin{array}{l}0,16 \\
0,19 \\
0,17 \\
\end{array}$ & $\begin{array}{r}100,0 \\
100,0 \\
32,1 \\
\end{array}$ & $\begin{array}{l}0,85 \\
0,77 \\
0,25 \\
\end{array}$ & $\begin{array}{r}2148,4 \\
1431,8 \\
638,3 \\
\end{array}$ & $\begin{array}{r}155,1 * \\
87,4 * \\
14,4 *\end{array}$ \\
\hline $\begin{array}{c}\text { 30 DAE } \\
\text { População de plantas } \\
-9 \text { dias } \\
0 \text { dia } \\
\text { +8 dias }\end{array}$ & $\begin{array}{l}4,51 \\
2,60 \\
1,37\end{array}$ & $\begin{array}{r}100,0 \\
100,0 \\
40,2 \\
\end{array}$ & $\begin{array}{r}0,81 \\
0,81 \\
0,09\end{array}$ & $\begin{array}{r}2652,0 \\
1153,3 \\
775,6\end{array}$ & $\begin{array}{r}123,4 * \\
111,4 * \\
10,9 *\end{array}$ \\
\hline $\begin{array}{l}\text { Massa seca } \\
\qquad 9 \text { dias } \\
0 \text { dia } \\
+8 \text { dias }\end{array}$ & $\begin{array}{l}0,07 \\
0,06 \\
0,04\end{array}$ & $\begin{array}{r}100,0 \\
100,0 \\
53,1\end{array}$ & $\begin{array}{l}0,57 \\
0,55 \\
0,04\end{array}$ & $\begin{array}{r}6075,4 \\
2777,8 \\
815,2\end{array}$ & $\begin{array}{l}47,1 * \\
39,2^{*} \\
10,1^{*}\end{array}$ \\
\hline $\begin{array}{l}\text { Cobertura do solo } \\
-9 \text { dias } \\
0 \text { dia } \\
+8 \text { dias }\end{array}$ & $\begin{array}{l}0,08 \\
0,08 \\
0,09\end{array}$ & $\begin{array}{r}100,0 \\
100,0 \\
28,1\end{array}$ & $\begin{array}{l}0,89 \\
0,57 \\
0,17\end{array}$ & $\begin{array}{r}1536,3 \\
2688,3 \\
700,6\end{array}$ & $\begin{array}{r}221,7 * \\
40,9 * \\
13,4 *\end{array}$ \\
\hline
\end{tabular}

1/ $i$ e $a$ = perda de rendimento (\%) por unidade do cultivar simulador quando o valor da variável se aproxima de zero ou tende ao infinito, respectivamente; ${ }^{2 /}$ dias após a emergência do arroz cultivado; e ${ }^{3 /}$ épocas de emergência do cultivar simulador em relação à do arroz cultivado. * Significativo a $5 \%$ de probabilidade.

relevante na perda de rendimento (Tabelas 1 e 2). Desse modo, as regras de decisão para controlar arroz-vermelho devem, necessariamente, considerar a época relativa de sua emergência junto à cultura.

Considerando como rendimento médio do arroz irrigado no Estado do Rio Grande do Sul $5.200 \mathrm{~kg} \mathrm{ha}^{-1}$ (IRGA, 2002), preço médio de 13 dólares $50 \mathrm{~kg}^{-1}$ (IRGA, 2002) e controle de plantas daninhas em lavouras de arroz ao custo de 65 dólares ha ${ }^{-1}$ (IRGA, 2002), estimase que o custo de controle equivale a $5 \%$ da produção. Assim, utilizando a variável população de plantas de arroz concorrente e tendo por base o parâmetro $i$, na avaliação de 15 dias após a emergência da cultura (Tabelas 1 e 2), estima-se que populações de $0,4,1,2$ e 3 plantas $\mathrm{m}^{-2}$ de arroz-vermelho ou 1,0, 4,0 e 4,4 plantas $\mathrm{m}^{-2}$ do arroz simulador, respectivamente para primeira, segunda e terceira épocas de emergência, apresentam perdas de rendimento por interferência equivalentes ao valor do custo de controle. Esses valores indicam que o arroz-vermelho é muito competitivo mesmo em baixas populações e que medidas de controle que eliminem até $99 \%$ da infestação podem não ser suficientes para evitar perdas de rendimento que superem o custo do controle.

A maioria dos modelos matemáticos desenvolvidos para estimar a perda de rendimento da cultura descreve a relação entre 
cultura e plantas daninhas com base na população. No entanto, essa variável pode ser um estimador inadequado da perda de rendimento, por desconsiderar o tamanho das plantas daninhas e, conseqüentemente, a época de emergência destas, um fator reconhecidamente crítico na determinação dos efeitos competitivos (Chikoye \& Swanton, 1995). Kropff (1988) demonstrou, através de análise de modelagem, que a variação nas perdas de rendimento se deveu muito mais às diferenças entre épocas de emergência da cultura e das plantas daninhas do que às diferenças na população destas. Dessa forma, o modelo proposto posteriormente por Cousens et al. (1987) permite incorporar o efeito da época de emergência das plantas daninhas, de modo que se possa avaliá-lo integrado à sua população, na estimativa da perda de rendimento da cultura.

Para arroz-vermelho, o modelo matemático que incorpora população de plantas e época de emergência apresentou ajuste satisfatório $\left(R^{2}\right)$ e significância estatística $(F)$ para todas as variáveis avaliadas e épocas de emergência (Tabela 3). Os resultados obtidos para o parâmetro $i$ foram mais expressivos na variável população de plantas, mantendo a mesma tendência observada na análise individualizada de cada uma das épocas (Tabela 1). Os valores da assintota foram, novamente, superestimados pelo modelo, sendo então limitados a $100 \%$ da perda máxima para todos os casos estudados.

O parâmetro $c$, que representa o índice de competitividade da cultura, demonstrou que o arroz irrigado foi pouco competitivo com o arroz-vermelho (Tabela 3). Os valores negativos observados para este parâmetro podem ser atribuídos à emergência antecipada das plantas daninhas em relação à cultura (Kropff et al., 1992; Rizzardi et al., 2003) e/ou ao fato de o modelo integrar as três épocas de emergência do arroz-vermelho.

Em geral, foram obtidos melhores ajustes dos dados ao modelo com adoção das variáveis população de plantas e cobertura do solo. Em parte, o fato explica-se porque a massa seca foi avaliada em área correspondente apenas à metade da área amostrada para população e porque a avaliação de cobertura do solo engloba área praticamente total da parcela, o que deve reduzir o erro experimental. Além disso, em decorrência de a massa seca ser uma determinação destrutiva, sua relação com perda de rendimento não é tão direta como as outras duas variáveis.

Para o cultivar simulador de arroz-vermelho, o modelo de Cousens et al. (1987) também apresentou significância estatística em todas as variáveis estudadas (Tabela 3). Em geral, os três parâmetros do modelo, embora os valores absolutos se diferenciem, mostraram as mesmas tendências relativas entre os dois genótipos concorrentes estudados.

Novamente, a variável explicativa massa seca foi a menos satisfatória em estimar a perda de rendimento, comparando-se os valores de $\mathrm{R}^{2}$ e SQR obtidos (Tabela 3). É provável que a área amostrada para massa seca tenha sido muito reduzida. Por outro lado, como se trata de variável destrutiva, ela não coincide com a área amostrada para rendimento de grãos.

Por este modelo, o parâmetro $i$ permite estimar que o arroz-vermelho foi 243, 216 e 195\% mais competitivo do que o cultivar simulador, respectivamente para as variáveis população de plantas, massa seca e cobertura do solo, nas médias das duas avaliações realizadas (Tabela 3).

A análise comparativa entre os genótipos competidores, com base na habilidade competitiva (i), revelou que o arroz-vermelho mostrou habilidade competitiva superior à do cultivar simulador, no caso das variáveis explicativas estudadas. Por outro lado, o parâmetro $c$, considerando-se apenas a variável população de plantas, indicou que a presença do arroz-vermelho ou do cultivar simulador resultou em indices de competitividade semelhantes.

Ao se compararem os dois modelos matemáticos, constatou-se que as perdas unitárias (i) estimadas pelo modelo que incorpora população e época de emergência, no caso da variável explicativa população de plantas na primeira avaliação, foram de 5,28 e 1,3\% para arroz-vermelho e cultivar simulador, respectivamente. Já o modelo que leva em conta somente a população de competidores, considerando-se a mesma variável e época de avaliação, estimou a perda unitária de rendimento, quando a emergência dos competidores 
Tabela 3 - Ajustes obtidos para perda do rendimento de grãos de arroz cultivado em função de população, massa seca da parte aérea e cobertura do solo de arroz-vermelho ou do cultivar EEA 406, simulador de arroz-vermelho. IRGA/CachoeirinhaRS, 1999/00

\begin{tabular}{|c|c|c|c|c|c|c|}
\hline \multirow{2}{*}{ Variável explicativa } & \multicolumn{3}{|c|}{ Parâmetro ${ }^{1 /}$} & \multirow{2}{*}{$\begin{array}{c}\text { Coeficiente de } \\
\text { determinação } \\
\left(\mathrm{R}^{2}\right)\end{array}$} & \multirow{2}{*}{$\begin{array}{c}\text { Soma de quadrados } \\
\text { do resíduo }\end{array}$} & \multirow{2}{*}{$\begin{array}{c}\text { Estatística } \\
\text { F }\end{array}$} \\
\hline & $i$ & $a$ & $c$ & & & \\
\hline \multicolumn{7}{|c|}{ Arroz-vermelho } \\
\hline $\begin{array}{c}15 \mathbf{D A E}^{\mathbf{2} /} \\
\text { População de plantas }\end{array}$ & 5,28 & 100 & $-0,09$ & 0,89 & $2.321,6$ & $150,1^{*}$ \\
\hline Massa seca & 1,06 & 100 & 0,003 & 0,87 & $2.761,1$ & $125,2^{*}$ \\
\hline Cobertura do solo & 0,50 & 100 & 0,007 & 0,91 & $1.945,7$ & $180,4^{*}$ \\
\hline $\begin{array}{c}\text { 30 DAE } \\
\text { População de plantas }\end{array}$ & 6,86 & 100 & $-0,06$ & 0,89 & $2.373,2$ & $146,7^{*}$ \\
\hline Massa seca & 0,11 & 100 & $-0,01$ & 0,77 & $4.976,9$ & $66,6^{*}$ \\
\hline Cobertura do solo & 0,15 & 100 & $-0,03$ & 0,87 & $2.803,1$ & $123,3^{*}$ \\
\hline \multicolumn{7}{|c|}{ Cultivar EEA 406} \\
\hline $\begin{array}{c}15 \text { DAE } \\
\text { População de plantas }\end{array}$ & 1,30 & 100 & $-0,11$ & 0,79 & $5.322,0$ & $134,7^{*}$ \\
\hline Massa seca & 0,32 & 100 & $-0,0003$ & 0,72 & $6.974,4$ & $98,4^{*}$ \\
\hline Cobertura do solo & 0,15 & 100 & $-0,01$ & 0,81 & $4.635,2$ & $157,4^{*}$ \\
\hline $\begin{array}{c}\text { 30 DAE } \\
\text { População de plantas }\end{array}$ & 2,25 & 100 & $-0,07$ & 0,81 & $4.762,1$ & $152,8^{*}$ \\
\hline Massa seca & 0,05 & 100 & $-0,03$ & 0,78 & $9.746,8$ & $65,2^{*}$ \\
\hline Cobertura do solo & 0,07 & 100 & $-0,01$ & 0,80 & $4.984,7$ & $145,1^{*}$ \\
\hline
\end{tabular}

${ }^{1 /} i=$ perda de rendimento (\%) por unidade do arroz-vermelho ou do cultivar simulador quando o valor da variável se aproxima de zero; $a=$ perda de rendimento (\%) por unidade do arroz-vermelho ou do cultivar simulador quando o valor da variável tende ao infinito; $c=$ parâmetro próprio do modelo; $\mathrm{e}^{\underline{2} /}$ dias após a emergência do arroz cultivado. * Significativo a $5 \%$ de probabilidade.

foi simultânea à do arroz irrigado, em 4,07 e $1,25 \%$ para arroz-vermelho e cultivar simulador, respectivamente (Tabelas 1, 2 e 3). Com base nesses dados, verifica-se que o modelo de dois parâmetros elevou em 30 e 4\% a estimativa de perda unitária de rendimento para arroz-vermelho e cultivar simulador, respectivamente, demonstrando ser este mais adequado que o modelo de um único parâmetro na predição da perda de rendimento do arroz irrigado.

Diante dos resultados apresentados, conclui-se que a emergência antecipada de plantas concorrentes, arroz-vermelho ou cultivar simulador, em relação à emergência do arroz irrigado, aumenta as perdas de rendimento de grãos da cultura. O arroz-vermelho, comparativamente ao cultivar simulador EEA 406, apresenta maiores habilidade de competição e potencial de dano à cultura do arroz. O cultivar de arroz IRGA 417 demonstra baixa habilidade de competição com arroz-vermelho ou com o cultivar EEA 406, simulador de sua presença. As perdas de rendimento de arroz por influência de arroz-vermelho e cultivar concorrente podem ser estimadas adequadamente pelo modelo da hipérbole retangular que incorpora as variáveis população de plantas e época de sua emergência com relação à cultura. População de plantas e cobertura do solo apresentam maior precisão do que massa seca de plantas como variáveis explicativas em modelos matemáticos destinados a estimar perdas de rendimento de grãos em arroz irrigado por arroz-vermelho ou cultivar simulador.

\section{LITERATURA CITADA}

AGOSTINETTO, D. et al. Arroz vermelho: ecofisiologia e manejo. Ci. Rural, v. 31, n. 2, p. 341-349, 2001.

ASKEW, S. D.; WILCUT, J. W. Pale smartweed interference and achene production in cotton. Weed Sci., v. 50, n. 3, p. $357-363,2002$. 
ASKEW, S. D.; WILCUT, J. W. Tropic croton interference in cotton. Weed Sci., v. 49, n. 2, p. 184-189, 2001.

CARRANZA, P.; SAAVEDRA, M.; GARCIA-TORRES, L. Competition between Ridolfia segetum and sunflower. Weed Res., v. 35, n. 5, p. 369-375, 1995.

CHIKOYE, D.; SWANTON, C. J. Evaluation of three empirical models depicting Ambrosia artemisiifolia competition in white bean. Weed Res., v. 35, n. 5, p. 421$428,1995$.

COUSENS, R. An empirical model relating crop yield to weed and crop density and a statistical comparison with other models. J. Agric. Sci., v. 105, n. 3, p. 513-521, 1985.

COUSENS, R. et al. The use of biologically realistic equations to describe the effects of weed density and relative time of emergence on crop yield. Weed Sci., v. 35, n. 5, p. 720-725, 1987.

\section{EMPRESA BRASILEIRA DE PESQUISA} AGROPECUÁRIA - EMBRAPA. Arroz irrigado: recomendações técnicas da pesquisa para o Sul do Brasil. Pelotas: Embrapa Clima Temperado/IRGA/EPAGRI, 1999. 124 p. (Embrapa Clima Temperado. Documento, 57).

INSTITUTO RIOGRANDENSE DO ARROZ - IRGA. Arroz irrigado no RS - área, produção e rendimento. Disponível em <http://www.irga.rs.gov.br>. Acesso em 5 out. 2002.

KNEZEVIC, S. Z.; HORAK, M. J.; VANDERLIP, R. L. Relative time of redroot pigweed (Amaranthus retroflexus L.) emergence is critical in pigweed-sorghum [Sorghum bicolor (L.) Moench] competition. Weed Sci., v. 45, n. 4, p. 502-508, 1997.

KROPFF, M. J. Modelling the effects of weeds on crop production. Weed Res., v. 28, n. 5, p. 467-471, 1988.

KROPFF, M. J.; LOTZ, L. A. P. Optimization of weed management systems: the role of ecological models of interplant competition. Weed Technol., v. 6, n. 2, p. 462470, 1992.
KROPFF, M. J.; WEAVER, S. E.; SMITS, M. A. Use of ecophysiological models for crop-weed interference: relations amongst weed density, relative time of weed emergence, relative leaf area, and yield loss. Weed Sci., v. 40, n. 2, p. 296-301, 1992.

O'DONOVAN, J. T. et al. Influence of the relative time of emergence of wild oat (Avena fatua) on yield loss of barley (Hordeum vulgare) and wheat (Triticum aestivum). Weed Sci., v. 33, n. 4, p. 498-503, 1985.

RADOSEVICH, S.; HOLT, J.; GHERSA, C. Weed ecology: implications for management. 2.ed. New York: Wiley, 1997. $588 \mathrm{p}$.

RATKOWSKY, D. A. Nonlinear regression modeling: a unified practical approach. New York: Marcel Dekker. 1983. $467 \mathrm{p}$.

RIZZARDI, M. A. et al. Ajuste de modelo para quantificar o efeito de plantas daninhas e época de semeadura no rendimento de soja. Pesq. Agrop. Brás., v. 38, n. 1, p. 35$43,2003$.

SAS INSTITUTE. INSTITUTE STATISTICAL ANALYSIS SYSTEM. User's guide: version 6. 4.ed. Cary: 1989. $846 \mathrm{p}$.

STREIBIG, J. C. et al. Estimation of thresholds for weed control in Australian cereals. Weed Res., v. 29, n. 2, p. $117-$ 126, 1989.

SWINTON, S. M. et al. Estimation of crop yield loss due to interference by multiple weed species. Weed Sci., v. 42, n. 1, p. 103-109, 1994.

VANDEVENDER, K. W.; COSTELLO, T. A.; SMITH JR., R. J. Model of rice (Oryza sativa) yield reduction as a function of weed interference. Weed Sci., v. 45, n. 2, p. 218-224, 1997.

WIESE, A. M.; BINNING, L. K. Calculating the threshold temperature of development for weeds. Weed Sci., v. 35, n. 2, p. 177-179, 1987.

YENISH, J. P. et al. Wheat (Triticum aestivum) yield reduction from common milkweed (Asclepias syriaca) competition. Weed Sci., v. 45, n. 1, p. 127-131, 1997. 